Received on 11 September, 2013; received in revised form, 17 October, 2013; accepted, 09 January, 2014; published 01 February, 2014

\title{
SYNTHESIS OF NOVEL 1, 5-DIHYDROBENZOTHIAZEPINE DERIVATIVES BY CONVENTIONAL AND MICROWAVE IRRADIATION METHODS AND THEIR PHARMACOLOGICAL ACTIVITIES
}

Venkata Rao Vutla*1, Rajendra Prasad Yejella ${ }^{2}$ and Ramarao Nadendla ${ }^{1}$

Department of Pharmaceutical Chemistry, Chalapathi Institute of Pharmaceutical Sciences ${ }^{1}$, Lam, Guntur, Andhra Pradesh, India

Department of Pharmaceutical Chemistry, University College of Pharmaceutical Sciences , Andhra University

${ }^{2}$, Visakhapatnam, Andhra Pradesh, India

Keywords:

4-Fluoroacetophenone, 1, 5-

DihydroBenzothiazepine, 2-

Aminothiophenol, piperidine, microwave irradiation

Correspondence to Author:

Venkata Rao Vutla

Associate Professor, Department of Pharmaceutical Chemistry,

Chalapathi Institute of

Pharmaceutical Sciences, Lam,

Guntur, Andhra Pradesh, India

Email: vvrao_pharma@yahoo.co.in
ABSTRACT: 1， 5-Dihydrobenzothiazepines are synthesized by conventional and microwave assisted synthesis methods. By microwave assisted synthesis, a considerable increase in the reaction rate has been observed and that too, with better yields. The compounds have been screened for antimicrobial and cytotoxic activity. 1, 5Dihydrobenzothiazepines are prepared by the reaction of 1, 3diarylprop-2-enones with o-aminothiophenol. All the products were tested for purity by tlc and characterized by elemental analysis, IR, ${ }^{1} \mathrm{H}$ $\mathrm{NMR},{ }^{13} \mathrm{C}-\mathrm{NMR}$ and mass spectral studies.
INTRODUCTION: The 1, 5-benzothiazepines ${ }^{1}$ (1and 2) are important nitrogen- and sulfurcontaining seven-membered heterocyclic compounds in drug research since they possess diverse bioactivities ${ }^{2-9}$.

1,5-Benzothiazepines are the most well-known representatives of benzologs of 1, 4-thiazepine (3) and one of the three possible benzo-condensed derivatives, viz. 1, 4-(4), 4,1- (5) and 1, 5benzothiazepines ${ }^{10-13}$.

\begin{tabular}{|l|l|}
\hline QUICK RESPONSE CODE & DOI: \\
\hline DOI link: http://dx.doi.org/10.13040/IJPSR.0975-8232.5(2).453-62 \\
\hline
\end{tabular}<smiles>C1=Nc2ccccc2SCC1</smiles>

(1)

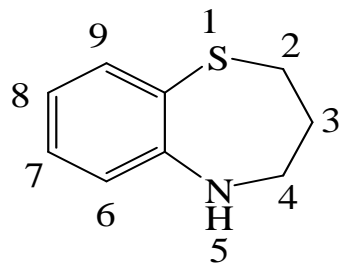

(2)

GENERAL STRUCTURES OF 1, 5-BENZOTHIAZEPINE<smiles>CN1C=CC=CSC1</smiles>

(3)<smiles>CS1=CC=NC=C2C=CC=C=C21</smiles>

(4) 


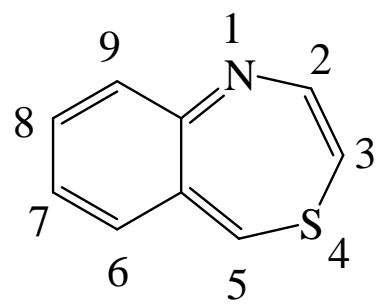

(5)

The 1, 5-benzothiazepine derivatives are of particular interest for lead discovery because they have been found active against different families of targets 14-24. The first molecule of 1, 5benzothiazepine used clinically was diltiazem (6), followed by clentiazem (7), for their cardiovascular action. Some of the 1, 5-benzothiazepine derivatives were also used clinically for CNS disorders which includes thiazesim (8), clothiapine (9) and quetiapine (10). Therefore, the 1,5Dihydrobenzothiazepines are useful compounds in the drug research which has stimulated the invention of a wide range of synthetic methods for their preparation and chemical transformations ${ }^{25-45}$.

Microwave-induced organic reaction enhancement (MORE) chemistry is gaining popularity as a non- conventional technique for rapid organic synthesis. Important features of this technique are easy access to very high temperature, good control over energy input in a reaction; higher yields and rapid synthesis of organic compounds. The synthesized compounds were purified by recrystallization and chromatography. The compounds were characterized by $1 \mathrm{H}$ NMR and IR analysis. The compounds were tested for their antimicrobial and cytotoxic activity by standard methods.

MATERIALS AND METHODS: All the chemicals used in the work were of analytical grade and procured from sigma Aldrich, Visakhapatnam.

a) General procedure for synthesis of 1,5 benzothiazepines (BP-1-20): To a solution of chalcone derivative in dry acidic methanol acidified by adding few drops of glacial acetic acid to it, 2-aminothiophenol was added. The mixture was then refluxed until a crystalline solid separates out. After cooling, the solid product was collected and washed with diethyl ether and cold methanol. The crude solid was recrystallized from ethanol.

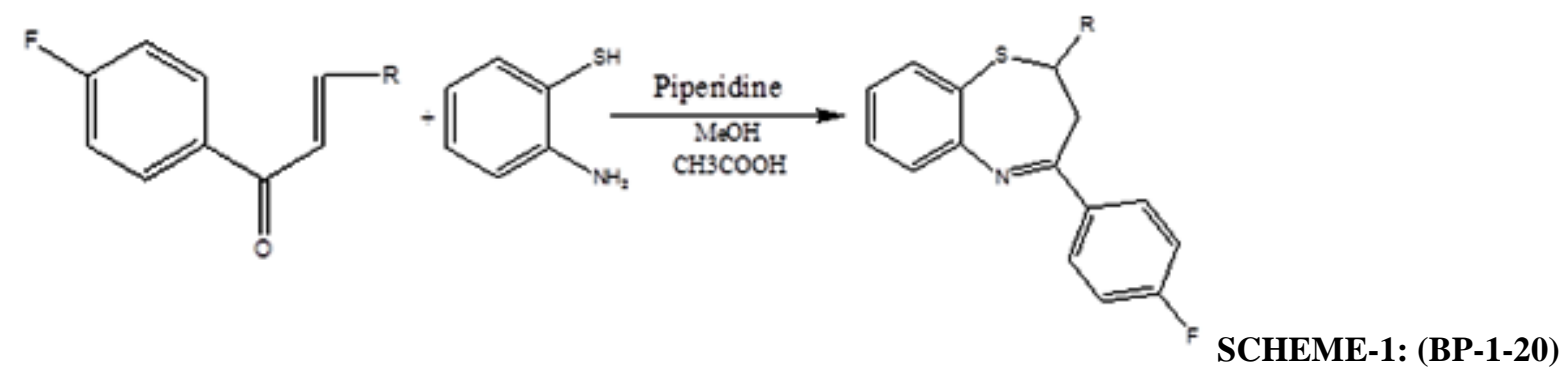

b) General procedure for synthesis of 1,5 benzothiazepines (BP-1-20) by Microwave irradiation method: Equimolar quantities $(0.001 \mathrm{~mol})$ of chalcone derivatives and 2-aminothiopheno (0.001 mol) were mixed and dissolved in minimum amount $(3 \mathrm{ml})$ of glacial acetic acid 1 . To this, piperidine $(0.003 \mathrm{~mol})$ was added slowly and mixed. The entire reaction mixture was microwave irradiated for about 2-6 min at 180 watts. Physical characterization data and Elemental Analysis data of 1, 5-benzothiazepines were represented in table1 and 2.

TABLE 1: PHYSICAL CHARACTERIZATION DATA OF 1, 5-BENZOTHIAZEPINES (BP 1 -BP $\left.{ }_{20}\right)$

\begin{tabular}{c|c|c|c|c|c}
\hline Compound & $\mathbf{R}$ & Molecular Formula & $\begin{array}{c}\text { Relative Molecular } \\
\text { Mass (RMM) }\end{array}$ & $\begin{array}{c}\text { Melting Point } \\
\left({ }^{\circ} \mathbf{C}\right)\end{array}$ & $\begin{array}{c}\text { Yield } \\
\text { \% }\end{array}$ \\
\hline $\mathbf{B P}_{1}$ & & $\mathrm{C}_{22} \mathrm{H}_{18} \mathrm{FNS}$ & 347.45 & $141-143$ & 89 \\
\hline $\mathbf{B P}_{\mathbf{2}}$ & & $\mathrm{C}_{21} \mathrm{H}_{15} \mathrm{~F}_{2} \mathrm{NS}$ & 351.41 & $152-154$ & 89 \\
\hline
\end{tabular}


Vutla et al., IJPSR, 2014; Vol. 5(2): 453-462.

E-ISSN: 0975-8232; P-ISSN: 2320-5148

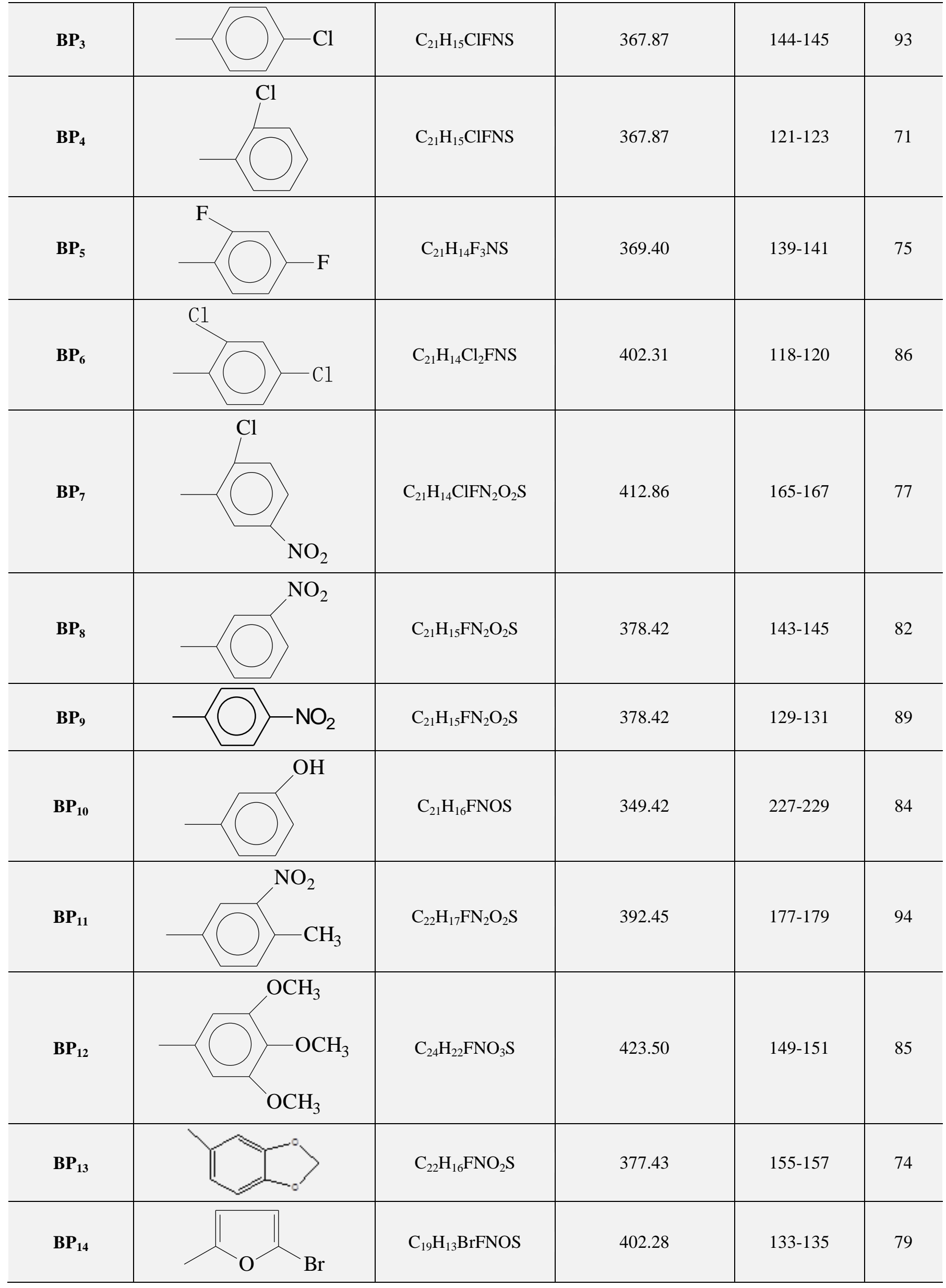




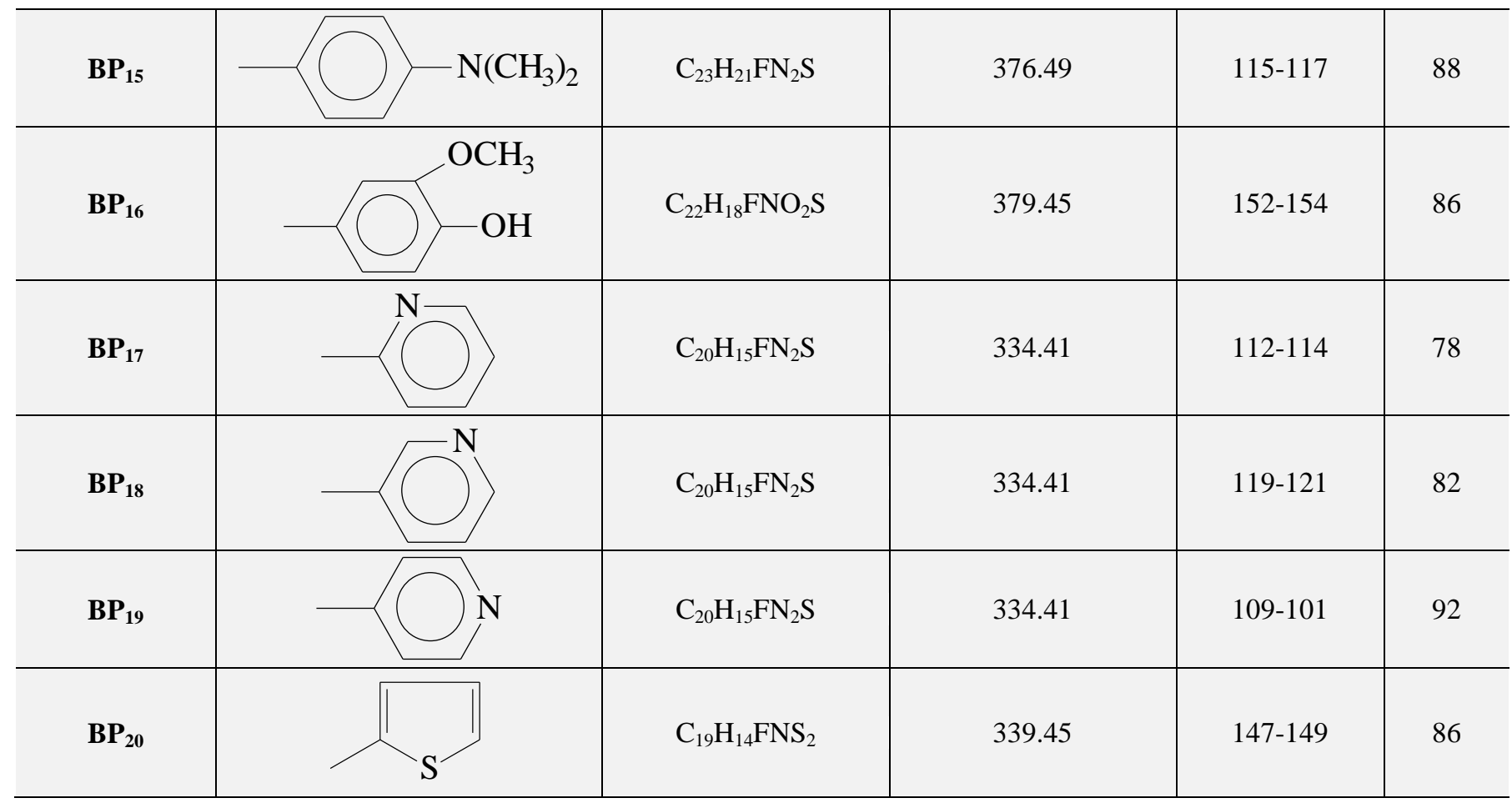

TABLE 2: ELEMENTAL ANALYSIS DATA OF 1,5-BENZOTHIAZEPINES $\left(\mathrm{BP}_{1}-\mathrm{BP}_{20}\right)$

\begin{tabular}{lcccccc}
\hline \multirow{2}{*}{ Compound } & \multicolumn{3}{c}{ \%Calculated } & \multicolumn{3}{c}{ \%Found } \\
\cline { 2 - 7 } & $\mathbf{C}$ & $\mathbf{H}$ & $\mathbf{N}$ & $\mathbf{C}$ & $\mathbf{H}$ & $\mathbf{N}$ \\
\hline $\mathbf{B P}_{\mathbf{1}}$ & 76.05 & 5.22 & 4.03 & 76.07 & 5.17 & 4.09 \\
$\mathbf{B P}_{\mathbf{2}}$ & 71.77 & 4.30 & 3.99 & 71.72 & 4.32 & 3.91 \\
$\mathbf{B P}_{\mathbf{3}}$ & 68.56 & 4.11 & 3.81 & 68.46 & 4.09 & 3.77 \\
$\mathbf{B P}_{\mathbf{4}}$ & 68.56 & 4.11 & 3.81 & 68.51 & 4.10 & 3.77 \\
$\mathbf{B P}_{\mathbf{5}}$ & 68.28 & 3.82 & 3.79 & 68.29 & 3.77 & 3.69 \\
$\mathbf{B P}_{\mathbf{6}}$ & 62.69 & 3.51 & 3.48 & 62.72 & 3.49 & 3.38 \\
$\mathbf{B P}_{\mathbf{7}}$ & 62.69 & 3.51 & 3.48 & 62.74 & 3.46 & 3.41 \\
$\mathbf{B P}_{\mathbf{8}}$ & 66.65 & 4.00 & 7.40 & 66.62 & 4.04 & 7.43 \\
$\mathbf{B P}_{\mathbf{9}}$ & 66.65 & 4.00 & 7.40 & 66.67 & 4.01 & 7.42 \\
$\mathbf{B P}_{\mathbf{1 0}}$ & 72.18 & 4.62 & 4.01 & 72.11 & 4.61 & 4.07 \\
$\mathbf{B P}_{\mathbf{1 1}}$ & 67.33 & 4.37 & 7.14 & 67.37 & 4.31 & 7.16 \\
$\mathbf{B P}_{\mathbf{1 2}}$ & 68.07 & 5.24 & 3.31 & 68.11 & 5.21 & 3.39 \\
$\mathbf{B P}_{\mathbf{1 3}}$ & 70.01 & 4.27 & 3.71 & 70.09 & 4.29 & 3.69 \\
$\mathbf{B P}_{\mathbf{1 4}}$ & 56.73 & 3.26 & 3.48 & 56.77 & 3.20 & 3.42 \\
$\mathbf{B P}_{\mathbf{1 5}}$ & 73.37 & 5.62 & 7.44 & 73.33 & 5.67 & 7.49 \\
$\mathbf{B P}_{\mathbf{1 6}}$ & 69.64 & 4.78 & 3.69 & 69.65 & 4.77 & 3.61 \\
$\mathbf{B P}_{\mathbf{1 7}}$ & 71.83 & 4.52 & 8.38 & 71.86 & 4.54 & 8.33 \\
$\mathbf{B P}_{\mathbf{1 8}}$ & 71.83 & 4.52 & 8.38 & 71.81 & 4.56 & 8.35 \\
$\mathbf{B P}_{\mathbf{1 9}}$ & 71.83 & 4.52 & 8.38 & 71.85 & 4.59 & 8.33 \\
$\mathbf{B P}_{\mathbf{2 0}}$ & 67.23 & 4.16 & 4.13 & 67.25 & 4.12 & 4.11 \\
\hline
\end{tabular}

Spectral Data for 1,5 -benzothiazepines $\left(\mathbf{B P}_{1^{-}}\right.$ $\left.\mathbf{B P}_{20}\right)$ are given below:

\section{BP-1:}

\section{2,3-Dihydro-2-(4-methylphenyl)-4-(4-fluoro} phenyl)-1,5-benzothiazepine (BP $)$ : Mol.wt: 347.45,yield: $89 \%$,mp: $141-143^{0} \mathrm{C}$,IR $(\mathrm{KBr})\left(\mathrm{cm}^{-1}\right)$
: $1585(\mathrm{C}=\mathrm{N}), 1505(\mathrm{C}=\mathrm{C}), 1395(\mathrm{C}-\mathrm{N}), 923(\mathrm{C}-\mathrm{F})$ and $654(\mathrm{C}-\mathrm{S}) .{ }^{1} \mathrm{H}-\mathrm{NMR}\left(\mathrm{CDCl}_{3}\right) \mathrm{ppm}: 4.94(\mathrm{dd}$, $\left.J_{2,3 a}=5.1 \mathrm{~Hz}, J_{2,3 b}=12 \mathrm{~Hz}, 1 \mathrm{H}, \mathrm{C}_{2}-\mathrm{H}\right), 3.25(\mathrm{dd}$, $\left.J_{3 a, 3 b}=14.4 \mathrm{~Hz}, J_{3 a, 2}=9.9 \mathrm{~Hz}, 1 \mathrm{H}, \mathrm{C}_{3}-\mathrm{H}-3 \mathrm{a}\right), 3.04$ $\left(\mathrm{t}, J_{3 b, 3 a}=J_{3 b, 2}=12.9 \mathrm{~Hz}, 1 \mathrm{H}, \mathrm{C}_{3}-\mathrm{H}-3 \mathrm{~b}\right), 2.40(3 \mathrm{H}$, $\left.\mathrm{s}, \mathrm{Ar}-\mathrm{CH}_{3}\right), 7.22(1 \mathrm{H}, \mathrm{s}, \mathrm{Ar}-\mathrm{H}), 7.61(3 \mathrm{H}, \mathrm{m}, \mathrm{Ar}-\mathrm{H})$, 7.20-8.10 (8H, Ar-H). 
BP-2:

2,3-Dihydro-2-(4-fluorophenyl)-4-(4-fluoro phenyl)-1,5-benzothiazepine $\left(\mathbf{B P}_{\mathbf{2}}\right)$ : $\mathrm{Mol}$. wt: 351.41' Yield: $89 \%$, M.P: $152-154^{\circ} \mathrm{C}$, IR (KBr) $\left.\left(\mathrm{cm}^{-1}\right): 1625 \quad(\mathrm{C}=\mathrm{N}), 1509 \quad(\mathrm{C}=\mathrm{C}), 1399 \quad \mathrm{C}-\mathrm{N}\right)$, 689(C-S), 931 (C-F), ${ }^{1} \mathrm{H}-\mathrm{NMR}\left(\mathrm{CDCl}_{3}\right) \mathrm{ppm}$ : $5.27\left(\mathrm{dd}, J_{2,3 a}=5.1 \mathrm{~Hz}, J_{2,3 b}=12 \mathrm{~Hz}, 1 \mathrm{H}, \mathrm{C}_{2^{-}}\right.$ $\mathrm{H}), 3.50\left(\mathrm{dd}, J_{3 a, 3 b}=14.4 \mathrm{~Hz}, J_{3 a, 2}=9.6 \mathrm{~Hz}, 1 \mathrm{H}, \mathrm{C}_{3}-\right.$ $\mathrm{H}-3 \mathrm{a}), 2.97\left(\mathrm{t}, J_{3 b, 3 a}=J_{3 b, 2}=12.9 \mathrm{~Hz}, 1 \mathrm{H}, \mathrm{C}_{3}-\mathrm{H}-\right.$ 3b), $7.05(1 \mathrm{H}, \mathrm{s}, \mathrm{Ar}-\mathrm{H}), 7.19(3 \mathrm{H}, \mathrm{m}, \mathrm{Ar}-\mathrm{H}), 7.20-$ $8.09(8 \mathrm{H}, \mathrm{Ar}-\mathrm{H})$.

\section{BP-3:}

2,3-Dihydro-2-(4-chlorophenyl)-4-(4-fluoro phenyl)-1,5-benzothiazepine $\left.\mathbf{( B P}_{\mathbf{3}}\right)$ : Mol. wt: 367.87, Yield: $93 \%$, M.P: $144-145^{\circ} \mathrm{C}$, IR (KBr) $\left(\mathrm{cm}^{-1}\right): 1595(\mathrm{C}=\mathrm{N}), 1502(\mathrm{C}=\mathrm{C}), 1384(\mathrm{C}-\mathrm{N})$, $778(\mathrm{C}-\mathrm{Cl}), 921(\mathrm{C}-\mathrm{F})$ and $667(\mathrm{C}-\mathrm{S}){ }^{1} \mathrm{H}-\mathrm{NMR}$ $\left(\mathrm{CDCl}_{3}\right) \mathrm{ppm}: 5.0\left(\mathrm{dd}, J_{2,3 a}=5.1 \mathrm{~Hz}, J_{2,3 b}=12 \mathrm{~Hz}\right.$, $\left.1 \mathrm{H}, \mathrm{C}_{2}-\mathrm{H}\right), 3.53\left(\mathrm{dd}, J_{3 a, 3 b}=14.4 \mathrm{~Hz}, J_{3 a, 2}=9.9 \mathrm{~Hz}\right.$, $\left.1 \mathrm{H}, \mathrm{C}_{3}-\mathrm{H}-3 \mathrm{a}\right), 3.39\left(\mathrm{t}, J_{3 b, 3 a}=J_{3 b, 2}=12.9 \mathrm{~Hz}, 1 \mathrm{H}\right.$, $\left.\mathrm{C}_{3}-\mathrm{H}-3 \mathrm{~b}\right), 7.25$ (1H, s, Ar-H), 7.65 (3H, m, Ar-H), 7.22-8.08 (8H, Ar-H).

\section{BP-4:}

2,3-Dihydro-2-(2-chlorophenyl)-4-(4-fluoro phenyl)-1,5-benzothiazepine (BP $\mathbf{4})$ : Mol. wt: 367.87, Yield: $71 \%$, M.P: $121-123^{\circ} \mathrm{C}$, IR (KBr) $\left(\mathrm{cm}^{-1}\right): 1596(\mathrm{C}=\mathrm{N}), 1510(\mathrm{C}=\mathrm{C}), 1365(\mathrm{C}-\mathrm{N}), 688$ (C-S), 923 (C-F) and 805 (C-Cl) ${ }^{1} \mathrm{H}-\mathrm{NMR}$ $\left(\mathrm{CDCl}_{3}\right)$ ppm: $4.89\left(\mathrm{dd}, J_{2,3 a}=5.1 \mathrm{~Hz}, J_{2,3 b}=12\right.$ $\mathrm{Hz}, 1 \mathrm{H}, \mathrm{C}_{2}-\mathrm{H}$ ), $3.43\left(\mathrm{dd}, J_{3 a, 3 b}=14.4 \mathrm{~Hz}, J_{3 a, 2}=9.6\right.$ $\left.\mathrm{Hz}, 1 \mathrm{H}, \mathrm{C}_{3}-\mathrm{H}-3 \mathrm{a}\right), 3.36\left(\mathrm{t}, J_{3 b, 3 a}=J_{3 b, 2}=12.9 \mathrm{~Hz}\right.$, $\left.1 \mathrm{H}, \mathrm{C}_{3}-\mathrm{H}-3 \mathrm{~b}\right), 7.12(1 \mathrm{H}, \mathrm{s}, \mathrm{Ar}-\mathrm{H}), 7.72(3 \mathrm{H}, \mathrm{m}, \mathrm{Ar}-$ $\mathrm{H})$, 6.95-7.60 (8H, Ar-H).

\section{BP-5:}

\section{2,3-Dihydro-2-(2,4-difluorophenyl)-4-(4-fluoro} phenyl)-1,5-benzothiazepine $\left(\mathbf{B P}_{5}\right)$ : Mol. wt: 369.40,yield:75\%, mp:139-141 ${ }^{0}$ C.IR $(\mathrm{KBr})\left(\mathrm{cm}^{-1}\right)$ : $1612(\mathrm{C}=\mathrm{N}), 1501(\mathrm{C}=\mathrm{C}), 1382(\mathrm{C}-\mathrm{N}), 689(\mathrm{C}-\mathrm{S})$, 913 (C-F) and 944 (C-F) ${ }^{1} \mathrm{H}-\mathrm{NMR}\left(\mathrm{CDCl}_{3}\right) \mathrm{ppm}$ : $5.31\left(\mathrm{dd}, J_{2,3 a}=5.1 \mathrm{~Hz}, J_{2,3 b}=12 \mathrm{~Hz}, 1 \mathrm{H}, \mathrm{C}_{2}-\mathrm{H}\right)$, $3.36\left(\mathrm{dd}, J_{3 a, 3 b}=14.4 \mathrm{~Hz}, J_{3 a, 2}=9.9 \mathrm{~Hz}, 1 \mathrm{H}, \mathrm{C}_{3}-\mathrm{H}-\right.$ 3a), 2.87 (t, $\left.J_{3 b, 3 a}=J_{3 b, 2}=12.9 \mathrm{~Hz}, 1 \mathrm{H}, \mathrm{C}_{3}-\mathrm{H}-3 \mathrm{~b}\right)$, 7.08 (1H, s, Ar-H), 7.30 (3H, m, Ar-H), 6.98-8.12 (7H, Ar-H).

\section{BP-6:}

2,3-Dihydro-2-(2,4-dichlorophenyl)-4-(4-fluoro phenyl)-1,5-benzothiazepine (BP $)$ : Mol. wt: 402.31,yield:86\%,mp: $118-120^{0} \mathrm{C}$. IR $(\mathrm{KBr})\left(\mathrm{cm}^{-1}\right)$ : $1593(\mathrm{C}=\mathrm{N}), 1502$ ( C=C), 1382 ( C-N), 687 (C$\mathrm{S}), 925(\mathrm{C}-\mathrm{F})$ and $805(\mathrm{C}-\mathrm{Cl}){ }^{1} \mathrm{H}-\mathrm{NMR}\left(\mathrm{CDCl}_{3}\right)$ ppm : $5.10\left(\mathrm{dd}, J_{2,3 a}=5.1 \mathrm{~Hz}, J_{2,3 b}=12 \mathrm{~Hz}, 1 \mathrm{H}\right.$, $\left.\mathrm{C}_{2}-\mathrm{H}\right), 3.27\left(\mathrm{dd}, J_{3 a, 3 b}=14.4 \mathrm{~Hz}, J_{3 a, 2}=9.6 \mathrm{~Hz}, 1 \mathrm{H}\right.$, $\left.\mathrm{C}_{3}-\mathrm{H}-3 \mathrm{a}\right), 2.66\left(\mathrm{t}, J_{3 b, 3 a}=J_{3 b, 2}=12.9 \mathrm{~Hz}, 1 \mathrm{H}, \mathrm{C}_{3}-\mathrm{H}-\right.$ 3b), $7.15(1 \mathrm{H}, \mathrm{s}, \mathrm{Ar}-\mathrm{H}), 7.20(3 \mathrm{H}, \mathrm{m}, \mathrm{Ar}-\mathrm{H}), 7.05-$ $7.95(7 \mathrm{H}, \mathrm{Ar}-\mathrm{H})$.

\section{BP-7:}

\section{2,3-Dihydro-2-(2-chloro-5-nitrophenyl)-4-(4-}

fluorophenyl)-1,5-benzothiazepine $\left(\mathrm{BP}_{7}\right)$ : $\mathrm{Mol}$. wt: 412.86 , Yield: $77 \%$, M.p: $165-167^{\circ} \mathrm{C}$,IR (KBr) $\left(\mathrm{cm}^{-1}\right): 1588(\mathrm{C}=\mathrm{N}), 1520(\mathrm{~N}=\mathrm{O}$, asymmetric $)$, $1505(\mathrm{C}=\mathrm{C}), 1382 \quad(\mathrm{C}-\mathrm{N}), 1340 \quad(\mathrm{~N}=\mathrm{O}$, symmetric), 656 ( C-S), 933 (C-F) and 781 (C-Cl), ${ }^{1} \mathrm{H}-\mathrm{NMR}\left(\mathrm{CDCl}_{3}\right) \mathrm{ppm}: 4.32\left(\mathrm{dd}, J_{2,3 a}=5.1 \mathrm{~Hz}\right.$, $\left.J_{2,3 b}=12 \mathrm{~Hz}, 1 \mathrm{H}, \mathrm{C}_{2}-\mathrm{H}\right), 3.74\left(\mathrm{dd}, J_{3 a, 3 b}=14.4 \mathrm{~Hz}\right.$, $\left.J_{3 a, 2}=9.9 \mathrm{~Hz}, 1 \mathrm{H}, \mathrm{C}_{3}-\mathrm{H}-3 \mathrm{a}\right), 3.51\left(\mathrm{t}, J_{3 b, 3 a}=J_{3 b, 2}=\right.$ $\left.12.9 \mathrm{~Hz}, 1 \mathrm{H}, \mathrm{C}_{3}-\mathrm{H}-3 \mathrm{~b}\right), 7.09$ (1H, s, Ar-H), 7.12 (3H, m, Ar-H), 6.98-8.10 (7H, Ar-H).

\section{BP-8:}

\section{2,3-Dihydro-2-(3-nitrophenyl)-4-(4-fluoro}

phenyl)-1,5-benzothiazepine (BP $)_{8}$ : Mol. wt: 378.42, Yield: $82 \%$, M.p: $143-145^{\circ} \mathrm{C}$, IR (KBr) (cm $\left.{ }^{1}\right)$ : $1580(\mathrm{C}=\mathrm{N}), 1522(\mathrm{~N}=\mathrm{O}$, asymmetric $), 1501$ ( $\mathrm{C}=\mathrm{C}), 1385$ ( C-N), 1345 ( $\mathrm{N}=\mathrm{O}$, symmetric), 924 (C-F) and 689 ( C-S), ${ }^{1} \mathrm{H}-\mathrm{NMR}\left(\mathrm{CDCl}_{3}\right) \mathrm{ppm}: 5.42$ $\left(\mathrm{dd}, J_{2,3 a}=5.1 \mathrm{~Hz}, J_{2,3 b}=12 \mathrm{~Hz}, 1 \mathrm{H}, \mathrm{C}_{2}-\mathrm{H}\right), 3.38$ $\left(\mathrm{dd}, J_{3 a, 3 b}=14.4 \mathrm{~Hz}, J_{3 a, 2}=9.6 \mathrm{~Hz}, 1 \mathrm{H}, \mathrm{C}_{3}-\mathrm{H}-3 \mathrm{a}\right)$, $2.86\left(\mathrm{t}, J_{3 b, 3 a}=J_{3 b, 2}=12.9 \mathrm{~Hz}, 1 \mathrm{H}, \mathrm{C}_{3}-\mathrm{H}-3 \mathrm{~b}\right), 7.30$ $(1 \mathrm{H}, \mathrm{s}, \mathrm{Ar}-\mathrm{H}), 7.80(3 \mathrm{H}, \mathrm{m}, \mathrm{Ar}-\mathrm{H}), 7.48-8.60(8 \mathrm{H}$, Ar-H).

\section{BP-9:}

\section{2,3-Dihydro-2-(4-nitrophenyl)-4-(4-fluoro}

phenyl)-1,5-benzothiazepine (BP9): Mol. wt: 378.42, Yield: $89 \%$, M.p: $129-131^{0} \mathrm{C}, \mathrm{IR}(\mathrm{KBr})\left(\mathrm{cm}^{-}\right.$ $\left.{ }^{1}\right)$ : $1586(\mathrm{C}=\mathrm{N}), 1515(\mathrm{~N}=\mathrm{O}$, asymmetric $), 1506$ ( $\mathrm{C}=\mathrm{C}), 1380 \quad$ ( C-N), 1338 ( $\mathrm{N}=\mathrm{O}$, symmetric), 925 (C-F) and 713 ( C-S), ${ }^{1} \mathrm{H}-\mathrm{NMR}\left(\mathrm{CDCl}_{3}\right) \mathrm{ppm}: 5.42$ $\left(\mathrm{dd}, J_{2,3 a}=5.1 \mathrm{~Hz}, J_{2,3 b}=12 \mathrm{~Hz}, 1 \mathrm{H}, \mathrm{C}_{2}-\mathrm{H}\right), 3.47$ $\left(\mathrm{dd}, J_{3 a, 3 b}=14.4 \mathrm{~Hz}, J_{3 a, 2}=9.7 \mathrm{~Hz}, 1 \mathrm{H}, \mathrm{C}_{3}-\mathrm{H}-3 \mathrm{a}\right)$, $3.10\left(\mathrm{t}, J_{3 b, 3 a}=J_{3 b, 2}=12.9 \mathrm{~Hz}, 1 \mathrm{H}, \mathrm{C}_{3}-\mathrm{H}-3 \mathrm{~b}\right), 7.18$ 
$(1 \mathrm{H}, \mathrm{s}, \mathrm{Ar}-\mathrm{H}), 7.25(3 \mathrm{H}, \mathrm{m}, \mathrm{Ar}-\mathrm{H}), 7.25-8.20(8 \mathrm{H}$, Ar-H).

\section{BP-10:}

\section{2,3-Dihydro-2-(3-hydroxyphenyl)-4-(4-fluoro}

phenyl)-1,5-benzothiazepine $\left(\mathbf{B P}_{10}\right)$ : Mol.wt: 349.42, Yield: $84 \%$, M.p: $227-229^{0} \mathrm{C}$,IR $(\mathrm{KBr})\left(\mathrm{cm}^{-}\right.$ $\left.{ }^{1}\right)$ : $1653(\mathrm{C}=\mathrm{N}), 1528$ ( C-N), $1502(\mathrm{C}=\mathrm{C}), 925$ (C-F) and $694(\mathrm{C}-\mathrm{S}),{ }^{1} \mathrm{H}-\mathrm{NMR}\left(\mathrm{CDCl}_{3}\right) \mathrm{ppm}: 3.85$ $\left(\mathrm{dd}, J_{2,3 a}=5.1 \mathrm{~Hz}, J_{2,3 b}=12 \mathrm{~Hz}, 1 \mathrm{H}, \mathrm{C}_{2}-\mathrm{H}\right), 3.34$ $\left(\mathrm{dd}, J_{3 a, 3 b}=14.4 \mathrm{~Hz}, J_{3 a, 2}=9.0 \mathrm{~Hz}, 1 \mathrm{H}, \mathrm{C}_{3}-\mathrm{H}-3 \mathrm{a}\right.$ ), $2.41\left(\mathrm{t}, J_{3 b, 3 a}=J_{3 b, 2}=12.9 \mathrm{~Hz}, 1 \mathrm{H}, \mathrm{C}_{3}-\mathrm{H}-3 \mathrm{~b}\right), 7.25$ $(1 \mathrm{H}, \mathrm{s}, \mathrm{Ar}-\mathrm{H}), 7.30(3 \mathrm{H}, \mathrm{m}, \mathrm{Ar}-\mathrm{H}), 7.15-7.80(8 \mathrm{H}$, Ar-H), 6.85 (1H, s, Ar-OH).

\section{BP-11:}

\section{2,3-Dihydro-2-(3-nitro-4-methylphenyl)-4-(4-} fluorophenyl)-1,5-benzothiazepine (BP $\left.\mathbf{B P}_{11}\right)$ : $\mathrm{Mol}$. wt: 392.45 , Yield: $94 \%$, M.p: $177-1798^{\circ} \mathrm{C}$,IR (KBr) $\left(\mathrm{cm}^{-1}\right): 1642(\mathrm{C}=\mathrm{N}), 1548(\mathrm{~N}=\mathrm{O}$, asymmetric $)$, $1510(\mathrm{C}=\mathrm{C}), 1380(\mathrm{C}-\mathrm{N}), 1338$ ( $\mathrm{N}=\mathrm{O}$, symmetric), 927 (C-F) and $668(\mathrm{C}-\mathrm{S}),{ }^{1} \mathrm{H}-\mathrm{NMR}\left(\mathrm{CDCl}_{3}\right) \mathrm{ppm}$ : $4.16\left(\mathrm{dd}, J_{2,3 a}=5.1 \mathrm{~Hz}, J_{2,3 b}=12 \mathrm{~Hz}, 1 \mathrm{H}, \mathrm{C}_{2}-\mathrm{H}\right)$, $3.23\left(\mathrm{dd}, J_{3 a, 3 b}=14.4 \mathrm{~Hz}, J_{3 a, 2}=9.9 \mathrm{~Hz}, 1 \mathrm{H}, \mathrm{C}_{3}-\mathrm{H}-\right.$ $3 \mathrm{a}), 2.53\left(\mathrm{t}, J_{3 b, 3 a}=J_{3 b, 2}=12.9 \mathrm{~Hz}, 1 \mathrm{H}, \mathrm{C}_{3}-\mathrm{H}-3 \mathrm{~b}\right.$ ), $2.50\left(3 \mathrm{H}, \mathrm{s}, \mathrm{Ar}-\mathrm{CH}_{3}\right), 7.30(1 \mathrm{H}, \mathrm{s}, \mathrm{Ar}-\mathrm{H}), 6.70(3 \mathrm{H}$, $\mathrm{m}, \mathrm{Ar}-\mathrm{H}), 7.45-8.78$ (7H, Ar-H)

\section{BP-12:}

\section{2,3-Dihydro-2-(3,4,5-trimethoxyphenyl)-4-(4-} fluorophenyl)-1,5-benzothiazepine (BP $\left.\mathbf{B P}_{12}\right)$ : $\mathrm{Mol}$. wt:423.50, Yield:8 \%, M.p: $149-151^{\circ} \mathrm{C}$, IR (KBr) $\left(\mathrm{cm}^{-1}\right)$ : $1648(\mathrm{C}=\mathrm{N}), 1505(\mathrm{C}=\mathrm{C}), 1365(\mathrm{C}-\mathrm{N})$, $1225\left(-\mathrm{O}-\mathrm{CH}_{3}\right), 923(\mathrm{C}-\mathrm{F})$ and $678(\mathrm{C}-\mathrm{S}),{ }^{1} \mathrm{H}-\mathrm{NMR}$ $\left(\mathrm{CDCl}_{3}\right) \mathrm{ppm}: 3.06\left(\mathrm{dd}, J_{2,3 a}=5.3 \mathrm{~Hz}, J_{2,3 b}=12\right.$ $\left.\mathrm{Hz}, 1 \mathrm{H}, \mathrm{C}_{2}-\mathrm{H}\right), 2.83\left(\mathrm{dd}, J_{3 a, 3 b}=14.4 \mathrm{~Hz}, J_{3 a, 2}=9.9\right.$ $\left.\mathrm{Hz}, 1 \mathrm{H}, \mathrm{C}_{3}-\mathrm{H}-3 \mathrm{a}\right), 2.0\left(\mathrm{t}, J_{3 b, 3 a}=J_{3 b, 2}=12.9 \mathrm{~Hz}\right.$, $\left.1 \mathrm{H}, \mathrm{C}_{3}-\mathrm{H}-3 \mathrm{~b}\right), 7.22(1 \mathrm{H}, \mathrm{s}, \mathrm{Ar}-\mathrm{H}), 6.60(3 \mathrm{H}, \mathrm{m}, \mathrm{Ar}-$ $\mathrm{H})$, 7.30-7.50 (6H, Ar-H), $3.70\left(3 \mathrm{H}, \mathrm{s}, \mathrm{Ar}-\mathrm{OCH}_{3}\right)$, $3.88\left(6 \mathrm{H}, \mathrm{s}, 2 \mathrm{XAr}-\mathrm{OCH}_{3}\right)$

\section{BP-13:}

2,3-Dihydro-2-(3,4-methelenedioxyphenyl)-4-(4fluorophenyl)-1,5-benzothiazepine $\quad\left(\mathbf{B P}_{13}\right)$ : Mol.wt:377.47, Yield: 74\%, M.p: $155-157^{\circ} \mathrm{C}$,IR $(\mathrm{KBr})\left(\mathrm{cm}^{-1}\right): 1592(\mathrm{C}=\mathrm{N}), 1502(\mathrm{C}=\mathrm{C}), 1370(\mathrm{C}-$ $\mathrm{N}), 1232$ (-O-CH $2-\mathrm{O}-), 921$ (C-F) and 689 (C-S), ${ }^{1} \mathrm{H}-\mathrm{NMR}\left(\mathrm{CDCl}_{3}\right) \mathrm{ppm}: 4.94\left(\mathrm{dd}, J_{2,3 a}=5.1 \mathrm{~Hz}\right.$,
$\left.J_{2,3 b}=12 \mathrm{~Hz}, 1 \mathrm{H}, \mathrm{C}_{2}-\mathrm{H}\right), 3.25\left(\mathrm{dd}, J_{3 a, 3 b}=14.4 \mathrm{~Hz}\right.$, $\left.J_{3 a, 2}=9.1 \mathrm{~Hz}, 1 \mathrm{H}, \mathrm{C}_{3}-\mathrm{H}-3 \mathrm{a}\right), 3.14\left(\mathrm{t}, J_{3 b, 3 a}=J_{3 b, 2}=\right.$ $\left.12.9 \mathrm{~Hz}, 1 \mathrm{H}, \mathrm{C}_{3}-\mathrm{H}-3 \mathrm{~b}\right), 7.25(1 \mathrm{H}, \mathrm{s}, \mathrm{Ar}-\mathrm{H}), 7.40$ $(3 \mathrm{H}, \mathrm{m}, \mathrm{Ar}-\mathrm{H}), 6.10$ (2H, s, O-CH$\left.{ }_{2}-\mathrm{O}\right), 7.21-7.85$ (7H, Ar-H)

\section{BP-14:}

2,3-Dihydro-2-(5-bromofuran-2-yl)-4-(4-fluoro phenyl)-1,5-benzothiazepine $\left(\mathbf{B P}_{\mathbf{1 4}}\right)$ : Mol. wt: 402.28, Yield: $79 \%$, M.p: $133-135^{\circ} \mathrm{C}$, IR (KBr) $\left(\mathrm{cm}^{-1}\right): 1602(\mathrm{C}=\mathrm{N}), 1505(\mathrm{C}=\mathrm{C}), 1340(\mathrm{C}-\mathrm{N}), 664$ (C-S), 933 (C-F) and 790 (C-Br) , ${ }^{1} \mathrm{H}-\mathrm{NMR}$ $\left(\mathrm{CDCl}_{3}\right) \mathrm{ppm}: 5.07\left(\mathrm{dd}, J_{2,3 a}=5.3 \mathrm{~Hz}, J_{2,3 b}=12\right.$ $\left.\mathrm{Hz}, 1 \mathrm{H}, \mathrm{C}_{2}-\mathrm{H}\right), 4.10\left(\mathrm{dd}, J_{3 a, 3 b}=14.4 \mathrm{~Hz}, J_{3 a, 2}=9.2\right.$ $\left.\mathrm{Hz}, 1 \mathrm{H}, \mathrm{C}_{3}-\mathrm{H}-3 \mathrm{a}\right), 3.39\left(\mathrm{t}, J_{3 b, 3 a}=J_{3 b, 2}=12.9 \mathrm{~Hz}\right.$, $\left.1 \mathrm{H}, \mathrm{C}_{3}-\mathrm{H}-3 \mathrm{~b}\right), 7.10(1 \mathrm{H}, \mathrm{s}, \mathrm{Ar}-\mathrm{H}), 6.80(3 \mathrm{H}, \mathrm{m}, \mathrm{Ar}-$ $\mathrm{H})$, 6.80-7.30 (6H, Ar-H)

\section{BP-15:}

2,3-Dihydro-2-(4-dimethylaminophenyl)-4-(4fluorophenyl)-1,5-benzothiazepine ( $\left.\mathbf{B P}_{15}\right)$ : $\mathrm{Mol}$. wt: 376.49 , Yield: $88 \%$, M.p: $115-117^{\circ} \mathrm{C}$, IR (KBr) $\left(\mathrm{cm}^{-1}\right)$ : $1608(\mathrm{C}=\mathrm{N}), 1509(\mathrm{C}=\mathrm{C}), 1390(\mathrm{C}-\mathrm{N})$, $1175\left(-\mathrm{N}-\left(\mathrm{CH}_{3}\right)_{2}\right), 933(\mathrm{C}-\mathrm{F})$ and $679(\mathrm{C}-\mathrm{S}), \mathrm{NMR}$ $\left(\mathrm{CDCl}_{3}\right) \mathrm{ppm}: 4.96\left(\mathrm{dd}, J_{2,3 a}=5.3 \mathrm{~Hz}, J_{2,3 b}=12\right.$ $\left.\mathrm{Hz}, 1 \mathrm{H}, \mathrm{C}_{2}-\mathrm{H}\right), 3.83\left(\mathrm{dd}, J_{3 a, 3 b}=14.4 \mathrm{~Hz}, J_{3 a, 2}=9.2\right.$ $\left.\mathrm{Hz}, 1 \mathrm{H}, \mathrm{C}_{3}-\mathrm{H}-3 \mathrm{a}\right), 3.26\left(\mathrm{t}, J_{3 b, 3 a}=J_{3 b, 2}=12.9 \mathrm{~Hz}\right.$, $\left.1 \mathrm{H}, \mathrm{C}_{3}-\mathrm{H}-3 \mathrm{~b}\right), 3.20\left(6 \mathrm{H}, \mathrm{s}, \mathrm{N}-\left(\mathrm{CH}_{3}\right)_{2}, 7.20(1 \mathrm{H}\right.$, s, Ar-H), 7.45 (3H, m, Ar-H), 6.70-8.20 (8H, Ar-H)

\section{BP-16:2,3-Dihydro-2-(3-methoxy-4-hydroxy} phenyl)-4-(4-fluorophenyl)-1,5-benzothiazepine (BP 16): Mol.wt:379.45, Yield: 86\%, M.p: 152$154^{0} \mathrm{C}$, , IR $(\mathrm{KBr})\left(\mathrm{cm}^{-1}\right): 3540(\mathrm{O}-\mathrm{H}), 1598(\mathrm{C}=\mathrm{N})$, $1502(\mathrm{C}=\mathrm{C}), 1378(\mathrm{C}-\mathrm{N}), 1234\left(-\mathrm{O}-\mathrm{CH}_{3}\right) 913(\mathrm{C}-$ $\mathrm{F})$, and $688(\mathrm{C}-\mathrm{S}) \mathrm{NMR}\left(\mathrm{CDCl}_{3}\right) \mathrm{ppm}: 3.43(\mathrm{dd}$, $\left.J_{2,3 a}=5.1 \mathrm{~Hz}, J_{2,3 b}=12 \mathrm{~Hz}, 1 \mathrm{H}, \mathrm{C}_{2}-\mathrm{H}\right), 2.50(\mathrm{dd}$, $\left.J_{3 a, 3 b}=14.4 \mathrm{~Hz}, J_{3 a, 2}=9.4 \mathrm{~Hz}, 1 \mathrm{H}, \mathrm{C}_{3}-\mathrm{H}-3 \mathrm{a}\right), 1.03$ $\left(\mathrm{t}, J_{3 b, 3 a}=J_{3 b, 2}=12.9 \mathrm{~Hz}, 1 \mathrm{H}, \mathrm{C}_{3}-\mathrm{H}-3 \mathrm{~b}\right), 7.20(1 \mathrm{H}$, s, Ar-H), 6.85 (3H, m, Ar-H), 7.15-7.90 (7H, Ar-H), $6.95(1 \mathrm{H}, \mathrm{s}, \mathrm{Ar}-\mathrm{OH}), 3.80\left(3 \mathrm{H}, \mathrm{s}, \mathrm{Ar}-\mathrm{O}-\mathrm{CH}_{3}\right)$

\section{BP-17:}

2,3-Dihydro-2-(2-pyridinyl)-4-(4-fluorophenyl)1,5-benzothiazepine (BP $\left.\mathbf{1 7}_{\mathbf{1 7}}\right)$ Mol.wt:334.41, Yield: 78\%, M.p: $112-114^{0} \mathrm{C}, 1602(\mathrm{C}=\mathrm{N}), 1510$ $(\mathrm{C}=\mathrm{C}), 1390(\mathrm{C}-\mathrm{N}), 924(\mathrm{C}-\mathrm{F})$ and $677(\mathrm{C}-\mathrm{S})$ ,NMR $\left(\mathrm{CDCl}_{3}\right) \mathrm{ppm}: 4.91\left(\mathrm{dd}, J_{2,3 a}=5.3 \mathrm{~Hz}, J_{2,3 b}\right.$ 
$\left.=12 \mathrm{~Hz}, 1 \mathrm{H}, \mathrm{C}_{2}-\mathrm{H}\right), 3.44\left(\mathrm{dd}, J_{3 a, 3 b}=14.4 \mathrm{~Hz}, J_{3 a, 2}\right.$ $\left.=9.4 \mathrm{~Hz}, 1 \mathrm{H}, \mathrm{C}_{3}-\mathrm{H}-3 \mathrm{a}\right), 1.05\left(\mathrm{t}, J_{3 b, 3 a}=J_{3 b, 2}=12.9\right.$ $\left.\mathrm{Hz}, 1 \mathrm{H}, \mathrm{C}_{3}-\mathrm{H}-3 \mathrm{~b}\right), 7.15(1 \mathrm{H}, \mathrm{s}, \mathrm{Ar}-\mathrm{H}), 7.20(3 \mathrm{H}, \mathrm{m}$, Ar-H), 7.10-8.15 (8H, Ar-H)

\section{BP-18:}

\section{2,3-Dihydro-2-(3-pyridinyl)-4-(4-fluorophenyl)-} 1,5-benzothiazepine $\quad$ BP $\left._{\mathbf{1 8}}\right)$ : Mol.wt:334.41, Yield: $82 \%$, M.p: $119-121^{0} \mathrm{C}$, IR (KBr) $\left(\mathrm{cm}^{-1}\right): 1599$ $(\mathrm{C}=\mathrm{N}), 1506(\mathrm{C}=\mathrm{C}), 1382(\mathrm{C}-\mathrm{N}), 927(\mathrm{C}-\mathrm{F})$ and 698 (C-S), NMR $\left(\mathrm{CDCl}_{3}\right) \mathrm{ppm}: 4.38\left(\mathrm{dd}, J_{2,3 a}=\right.$ $\left.5.3 \mathrm{~Hz}, J_{2,3 b}=12 \mathrm{~Hz}, 1 \mathrm{H}, \mathrm{C}_{2}-\mathrm{H}\right), 3.37\left(\mathrm{dd}, J_{3 a, 3 b}=\right.$ $\left.14.4 \mathrm{~Hz}, J_{3 a, 2}=9.8 \mathrm{~Hz}, 1 \mathrm{H}, \mathrm{C}_{3}-\mathrm{H}-3 \mathrm{a}\right), 1.07\left(\mathrm{t}, J_{3 b, 3 a}\right.$ $\left.=J_{3 b, 2}=12.9 \mathrm{~Hz}, 1 \mathrm{H}, \mathrm{C}_{3}-\mathrm{H}-3 \mathrm{~b}\right), 7.25(1 \mathrm{H}, \mathrm{s}, \mathrm{Ar}-\mathrm{H})$, $7.30(3 \mathrm{H}, \mathrm{m}, \mathrm{Ar}-\mathrm{H}), 6.75-8.90(8 \mathrm{H}, \mathrm{Ar}-\mathrm{H})$

\section{BP-19:}

\section{2,3-Dihydro-2-(4-pyridinyl)-4-(4-fluorophenyl)-} 1,5-benzothiazepine (BP $\left.{ }_{19}\right)$ : Mol.wt:334.41, Yield: $92 \%$, M.p: $109-111^{0} \mathrm{C}$, IR (KBr) $\left(\mathrm{cm}^{-1}\right): 1606$ $(\mathrm{C}=\mathrm{N}), 1508(\mathrm{C}=\mathrm{C}), 1388(\mathrm{C}-\mathrm{N}), 933(\mathrm{C}-\mathrm{F})$ and $654(\mathrm{C}-\mathrm{S})$, NMR $\left(\mathrm{CDCl}_{3}\right) \mathrm{ppm}: 4.67\left(\mathrm{dd}, J_{2,3 a}=\right.$ $\left.5.1 \mathrm{~Hz}, J_{2,3 b}=12 \mathrm{~Hz}, 1 \mathrm{H}, \mathrm{C}_{2}-\mathrm{H}\right), 3.42\left(\mathrm{dd}, J_{3 a, 3 b}=\right.$ $\left.14.4 \mathrm{~Hz}, J_{3 a, 2}=9.8 \mathrm{~Hz}, 1 \mathrm{H}, \mathrm{C}_{3}-\mathrm{H}-3 \mathrm{a}\right), 2.50\left(\mathrm{t}, J_{3 b, 3 a}\right.$ $\left.=J_{3 b, 2}=12.9 \mathrm{~Hz}, 1 \mathrm{H}, \mathrm{C}_{3}-\mathrm{H}-3 \mathrm{~b}\right), 7.20(1 \mathrm{H}, \mathrm{s}, \mathrm{Ar}-\mathrm{H})$, $7.50(3 \mathrm{H}, \mathrm{m}, \mathrm{Ar}-\mathrm{H}), 6.95-8.68(8 \mathrm{H}, \mathrm{Ar}-\mathrm{H})$

\section{BP-20:}

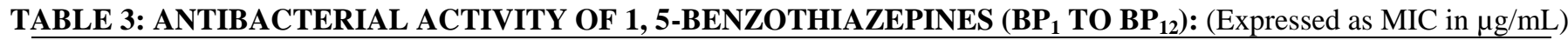

\begin{tabular}{|c|c|c|c|c|c|}
\hline Compound & $\mathbf{R}$ & B. subtilis & S. aureus & E. coli & P. vulgaris \\
\hline $\mathbf{B P}_{1}$ & 4"-methylphenyl & 256 & 128 & 128 & 128 \\
\hline $\mathbf{B P}_{2}$ & 4"-fluorophenyl & 128 & 128 & 256 & 128 \\
\hline $\mathbf{B P}_{3}$ & 4"-chlorophenyl & 64 & 256 & 128 & 128 \\
\hline $\mathbf{B P}_{4}$ & 2"-chlorophenyl & 128 & 64 & 128 & 128 \\
\hline $\mathbf{B P}_{5}$ & 2",4"-difluorophenyl & 64 & 64 & 32 & 64 \\
\hline $\mathbf{B P}_{6}$ & 2",4-dichlorophenyl & 64 & 128 & 64 & 128 \\
\hline $\mathbf{B P}_{7}$ & 2"-chloro-5"-nitrophenyl & 128 & 64 & 128 & 256 \\
\hline $\mathbf{B P}_{8}$ & 3"-nitrophenyl & 256 & 128 & 128 & 256 \\
\hline $\mathbf{B P}_{9}$ & 4"-nitrophenyl & 128 & 128 & 64 & 128 \\
\hline $\mathbf{B P}_{10}$ & 3"-hydroxyphenyl & 64 & 128 & 128 & 64 \\
\hline $\mathbf{B P}_{11}$ & 3"-nitro-4"-methylphenyl & 128 & 128 & 256 & 128 \\
\hline $\mathbf{B P}_{12}$ & 3",4",5"-trimethoxypheny & 128 & 128 & 64 & 128 \\
\hline $\mathbf{B P}_{13}$ & 3",4"-methylendioxyphenyl & 256 & 512 & 128 & 256 \\
\hline $\mathbf{B P}_{14}$ & 5"-bromofuran-2"-yl & 128 & 64 & 64 & 128 \\
\hline $\mathbf{B P}_{15}$ & 4"-dimethylaminophenyl & 64 & 64 & 128 & 64 \\
\hline $\mathbf{B P}_{16}$ & 3"-methoxy-4"-hydroxyphenyl & 128 & 256 & 256 & 128 \\
\hline $\mathbf{B P}_{17}$ & 2"-pyridinyl & 256 & 256 & 512 & 256 \\
\hline $\mathbf{B P}_{18}$ & 3"-pyridinyl & 256 & 128 & 256 & 128 \\
\hline $\mathbf{B P}_{19}$ & 4"-pyridinyl & 128 & 64 & 64 & 128 \\
\hline $\mathbf{B P}_{20}$ & 2"-thienyl & 256 & 128 & 128 & 64 \\
\hline Standard (Ampicillin) & & $<1$ & $<1$ & $<1$ & $<1$ \\
\hline
\end{tabular}

\section{2,3-Dihydro-2-(2-thienyl)-4-(4-fluorophenyl)-}

1,5-benzothiazepine $\left.\quad \mathbf{B P}_{\mathbf{2 0}}\right)$ : Mol.wt:339.45, Yield: $86 \%$, M.p: $147-149^{0} \mathrm{C}$, IR $(\mathrm{KBr})\left(\mathrm{cm}^{-1}\right): 1605$ $(\mathrm{C}=\mathrm{N}), 1503(\mathrm{C}=\mathrm{C}), 1386(\mathrm{C}-\mathrm{N}), 928(\mathrm{C}-\mathrm{F})$ and $644(\mathrm{C}-\mathrm{S}), \mathrm{NMR}\left(\mathrm{CDCl}_{3}\right) \mathrm{ppm}: 5.50\left(\mathrm{dd}, J_{2,3 a}=\right.$ $\left.5.3 \mathrm{~Hz}, J_{2,3 b}=12 \mathrm{~Hz}, 1 \mathrm{H}, \mathrm{C}_{2}-\mathrm{H}\right), 3.53\left(\mathrm{dd}, J_{3 a, 3 b}=\right.$ $\left.14.4 \mathrm{~Hz}, J_{3 a, 2}=9.9 \mathrm{~Hz}, 1 \mathrm{H}, \mathrm{C}_{3}-\mathrm{H}-3 \mathrm{a}\right), 2.90\left(\mathrm{t}, J_{3 b, 3 a}\right.$ $\left.=J_{3 b, 2}=12.9 \mathrm{~Hz}, 1 \mathrm{H}, \mathrm{C}_{3}-\mathrm{H}-3 \mathrm{~b}\right), 7.20(1 \mathrm{H}, \mathrm{s}, \mathrm{Ar}-\mathrm{H})$, 7.34 (3H, m, Ar-H), 6.60-7.80 (7H, Ar-H)

Antibacterial activity: The antibacterial activity was tested by determining the minimum inhibitory concentration (MIC) for each compound using Standard Serial Tube Dilution Technique. The organisms used are

Gram positive bacteria: Staphylococcus aureus (NCIM-2079), Bacillus subtilis (NCIM-2063)

Gram negative bacteria: Escherichia coli (NCIM-2068), Proteus vulgaris (NCIM-2027)

Antifungal activity: The antifungal activity was tested by the same procedure as described in the antibacterial activity, except using PotatoDextrose-Agar medium.

The organisms used are: Aspergillus niger (ATCC6275), Candida tropicalis (ATCC-1369)

The results are presented in Table 3 . 


\section{DISCUSSION ON RESULTS:}

Antibacterial activity: From the above results, it is evident that most of the 1,5-benzothiazepines synthesized showed antibacterial activity with different MIC values against the tested organisms, but not comparable with that of the standard. Among the compounds tested against B. subtilis, the compounds, $\mathrm{BP}_{3}$ having a chlorophenyl moiety, $\mathrm{BP}_{5}$ having a difluorophenyl moiety, $\mathrm{BP}_{6}$ having a dichlorophenyl moiety, $\mathrm{BP}_{10}$ having a hydroxyllphenyl and $\mathrm{BP}_{15}$ having a dimethylaminophenyl moiety proved to be more potent with a MIC value of $64 \mu \mathrm{g} / \mathrm{mL}$ in each case. Against S.aureus, $\mathrm{BP}_{4}$, $\mathrm{BP}_{5}, \mathrm{BP}_{7}$ (2-chloro-5-nitrophenyl moiety), $\mathrm{BP}_{14}$ (bromofuran moiety), $\mathrm{BP}_{15}$ and $\mathrm{BP}_{19}$ (4-pyridinyl moiety) showed maximum activity with a MIC value of $64 \mu \mathrm{g} / \mathrm{mL}$ in each case. Against E. coli $\mathrm{BP}_{5}$ proved to be the most potent with a MIC value of $32 \mu \mathrm{g} / \mathrm{mL}$. This is followed by compounds, $\mathrm{BP}_{6}$, $\mathrm{BP}_{9}$ (nitrophenyl moiety), $\mathrm{BP}_{12}$ (trimethoxyphenyl moiety), $\mathrm{BP}_{14}$ and $\mathrm{BP}_{19}$ with a $\mathrm{MIC}$ value of 64 $\mu \mathrm{g} / \mathrm{mL}$ in each case. Against P. vulgaris, $\mathrm{BP}_{5}, \mathrm{BP}_{10}$, $\mathrm{BP}_{15}$ and $\mathrm{BP}_{20}$ (thienyl moiety) showed maximum activity with a MIC value of $64 \mu \mathrm{g} / \mathrm{mL}$ in each case.

Procedure for Antifungal activity: The antifungal activity was tested by the same procedure as described in the antibacterial activity, except using Potato-Dextrose-Agar medium. The results are presented in Table 4.

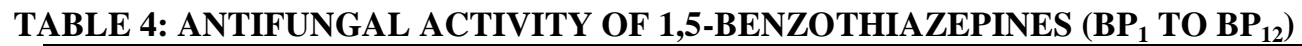

\begin{tabular}{cccc}
\hline Compound & $\mathbf{R}$ & Aspergillus niger & Candida tropicalis \\
\hline $\mathbf{B P}_{\mathbf{1}}$ & 4"-methylphenyl & 64 & 32 \\
$\mathbf{B P}_{\mathbf{2}}$ & $4 "-$-fluorophenyl & 32 & 64 \\
$\mathbf{B P}_{\mathbf{3}}$ & 4"-chlorophenyl & 32 & 34 \\
$\mathbf{B P}_{\mathbf{4}}$ & 2"-chlorophenyl & 32 & 64 \\
$\mathbf{B P}_{\mathbf{5}}$ & 2",4"-difluorophenyl & 16 & 16 \\
$\mathbf{B P}_{\mathbf{6}}$ & $2 ", 4-$ dichlorophenyl & 16 & 32 \\
$\mathbf{B P}_{\mathbf{7}}$ & 2"-chloro-5"-nitrophenyl & 16 & 32 \\
$\mathbf{B P}_{\mathbf{8}}$ & 3"-nitrophenyl & 32 & 128 \\
$\mathbf{B P}_{\mathbf{9}}$ & 4"-nitrophenyl & 32 & 64 \\
$\mathbf{B P}_{\mathbf{1 0}}$ & 3"-hydroxyphenyl & 256 & 128 \\
$\mathbf{B P}_{\mathbf{1 1}}$ & 3"-nitro-4"-methylphenyl & 128 & 64 \\
$\mathbf{B P}_{\mathbf{1 2}}$ & 3",4",5"-trimethoxypheny & 128 & 64 \\
$\mathbf{B P}_{\mathbf{1 3}}$ & 3",4"-methylendioxyphenyl & 128 & 64 \\
$\mathbf{B P}_{\mathbf{1 4}}$ & 5"-bromofuran-2"-yl & 16 & 32 \\
$\mathbf{B P}_{\mathbf{1 5}}$ & 4"-dimethylaminophenyl & 128 & 64 \\
$\mathbf{B P}_{\mathbf{1 6}}$ & 3"-methoxy-4"-hydroxyphenyl & 128 & 64 \\
$\mathbf{B P}_{\mathbf{1 7}}$ & 2"-pyridinyl & 32 & 64 \\
$\mathbf{B P}_{\mathbf{1 8}}$ & 3"-pyridinyl & 128 & 64 \\
$\mathbf{B P}_{\mathbf{1 9}}$ & 4"-pyridinyl & 16 & 32 \\
$\mathbf{B P}_{\mathbf{2 0}}$ & 2"-thienyl & 32 & 16 \\
Standard (Fluconazole) & & $<2$ & $<2$ \\
\hline
\end{tabular}

Antifungal activity: From the above results, It is noticed that the 1, 5-benzothiazepines tested showed more antifungal activity than the antibacterial activity. Among the compounds tested against $A$. niger, the compounds, $\mathrm{BP}_{5}$ having a difluorophenyl moiety, $\mathrm{BP}_{6}$ having a dichlorophenyl moiety, $\mathrm{BP}_{7}$ having a 2-chloro-5nitrophenyl moiety, $\mathrm{BP}_{14}$ having a bromofuran moiety and $\mathrm{BP}_{19}$ having a 4-pyridinyl moiety proved to be the most potent compounds with a MIC value of $16 \mu \mathrm{g} / \mathrm{mL}$ in each case. This was followed by the compounds, $\mathrm{BP}_{2}$ (fluorophenyl moiety), $\mathrm{BP}_{3}$ and $\mathrm{BP}_{4}$ (chlorophenyl moieties), $\mathrm{BP}_{8}$ and $\mathrm{BP}_{9}$ (nitrophenyl moieties), $\mathrm{BP}_{17}$ (2-pyridinyl moiety) and $\mathrm{BP}_{20}$ (thienyl moiety) with a $\mathrm{MIC}$ value of $32 \mu \mathrm{g} / \mathrm{mL}$ in each case. Against $C$. tropicalis, the compounds, $\mathrm{BP}_{5}$ and $\mathrm{BP}_{20}$, showed maximum activity with a MIC value of $16 \mu \mathrm{g} / \mathrm{mL}$ in each case.

This was followed by compounds, $\mathrm{BP}_{1}$ (methylphenyl), $\mathrm{BP}_{6}, \mathrm{BP}_{7}$ (2-chloro-5-nitrophenyl moiety), $\mathrm{BP}_{14}$ and $\mathrm{BP}_{19}$ with a $\mathrm{MIC}$ value of 32 $\mu \mathrm{g} / \mathrm{mL}$ in each case.

Cytotoxicity Studies: The in vitro cytotoxicity of the test compounds was evaluated by the MTT assay. HT-29 (colon cancer), MCF-7 (breast cancer) and DU-145 (prostate cancer) cell lines were obtained from ACTREC, Mumbai, India. 
Cytotoxicity evaluation: The cells were seeded in 96 well plates at a density of $1 \times 10^{4}$ (counted by Trypan blue exclusion dye method) per well and were incubated for $24 \mathrm{~h}$ to recover. After incubation the medium was replaced with fresh media containing different dilutions of the test compounds. Then the plated were incubated for additional $48 \mathrm{~h}$ at $37^{\circ} \mathrm{C}$ in DMEM/MEM with $10 \%$ FBS medium. Following incubation, the medium was removed and replaced with $90 \mu \mathrm{l}$ of fresh
DMEM without FBS. To the above wells, $10 \mu \mathrm{l}$ of MTT reagent $(5 \mathrm{mg} / \mathrm{mL}$ of stock solution in DMEM without FBS) was added and incubated at $37^{\circ} \mathrm{C}$ for $3-4 \mathrm{~h}$, there after the above media was replaced by adding $200 \mu \mathrm{l}$ of DMSO to each well and incubated at $37^{\circ} \mathrm{C}$ for $10 \mathrm{~min}$. The absorbance at $570 \mathrm{~nm}$ was measured on a spectrophotometer. Methotrexate was used as reference drug for comparison. The results are presented in Table 5.

TABLE 5: CYTOTOXICITY OF THE NEW 1,5-BENZOTHIAZEPINES (BP $\mathbf{T}_{\mathbf{1}}$ TO BP $\left._{\mathbf{1 1}}\right)$ : $\left(\mathrm{IC}_{50}\right.$ values in $\left.\mu \mathrm{g} / \mathrm{mL}\right)$

\begin{tabular}{|c|c|c|c|c|}
\hline \multirow{2}{*}{ Compound } & \multirow{2}{*}{$\mathbf{R}$} & \multicolumn{3}{|c|}{ Cell line } \\
\hline & & HT-29 & MCF-7 & DU-145 \\
\hline $\mathrm{BP}_{1}$ & 4"-methyl phenyl & $55 \pm 2$ & $62 \pm 2$ & $52 \pm 1$ \\
\hline $\mathrm{BP}_{2}$ & 4"-fluorophenyl & $42 \pm 2$ & $48 \pm 1$ & $62 \pm 2$ \\
\hline $\mathrm{BP}_{3}$ & 4"-chlorophenyl & $92 \pm 2$ & $78 \pm 2$ & $65 \pm 2$ \\
\hline $\mathrm{BP}_{4}$ & 2"-chlorophenyl & $105 \pm 2$ & $168 \pm 1$ & $122 \pm 2$ \\
\hline $\mathrm{BP}_{5}$ & 2",4"-difluorophenyl & $28 \pm 1$ & $42 \pm 2$ & $33 \pm 2$ \\
\hline $\mathrm{BP}_{6}$ & 2",4"-dichlorophenyl & $42 \pm 2$ & $67 \pm 1$ & $56 \pm 2$ \\
\hline $\mathrm{BP}_{7}$ & 2"-chloro-5"-nitrophenyl & $115 \pm 2$ & NA & NA \\
\hline $\mathrm{BP}_{8}$ & 3"-nitrophenyl & $180 \pm 2$ & NA & NA \\
\hline $\mathrm{BP}_{9}$ & 4"-nitrophenyl & $155 \pm 1$ & NA & $105 \pm 2$ \\
\hline $\mathrm{BP}_{10}$ & 3"-hydroxyphenyl & $148 \pm 2$ & $129 \pm 2$ & $155 \pm 1$ \\
\hline $\mathrm{BP}_{11}$ & 3"-nitro-4"methylphenyl & $64 \pm 2$ & $58 \pm 1$ & $46 \pm 2$ \\
\hline $\mathrm{BP}_{12}$ & 3",4",5"-trimethoxyphenyl & $132 \pm 2$ & NA & $93 \pm 2$ \\
\hline $\mathrm{BP}_{13}$ & 3",4"-methelenedioxyphenyl & NA & NA & $75 \pm 2$ \\
\hline $\mathrm{BP}_{14}$ & 5"-bromofuran-2"-yl & $56 \pm 2$ & $27 \pm 1$ & $16 \pm 1$ \\
\hline $\mathrm{BP}_{15}$ & 4"-dimethylaminophenyl & $182 \pm 1$ & $106 \pm 2$ & $98 \pm 2$ \\
\hline $\mathrm{BP}_{16}$ & 3"-methoxy-4"-hydroxyphenyl & $123 \pm 2$ & $74 \pm 1$ & $68 \pm 2$ \\
\hline $\mathrm{BP}_{17}$ & 2"-pyridinyl & $195 \pm 2$ & $140 \pm 1$ & $92 \pm 2$ \\
\hline $\mathrm{BP}_{18}$ & 3"-pyridinyl & NA & $188 \pm 2$ & $110 \pm 2$ \\
\hline $\mathrm{BP}_{19}$ & 4"-pyridinyl & $128 \pm 2$ & NA & $148 \pm 1$ \\
\hline $\mathrm{BP}_{20}$ & 2"-thienyl & $36 \pm 2$ & $28 \pm 1$ & $16 \pm 2$ \\
\hline Methotrexate & & $11 \pm 1$ & $9 \pm 1$ & $6 \pm 1$ \\
\hline
\end{tabular}

Data presented as mean \pm SD $(n=3)$. All the compounds and the standard dissolved in DMSO, diluted with culture medium containing $0.1 \%$ DMSO. The control cells were treated with culture medium containing $0.1 \%$ DMSO. NA- No Activity (i.e IC50 $>200 \mu \mathrm{g} / \mathrm{mL}$ )

\section{DISCUSSION ON RESULTS:}

Cytotoxic studies: Of all the compounds tested against HT-29 cell lines, the compound $\mathrm{BP}_{5}$ having a difluorophenyl moiety in its structure showed maximum activity with a $\mathrm{IC}_{50}$ value of $28 \mu \mathrm{g} / \mathrm{mL}$. This is followed by compounds, $\mathrm{BP}_{20}$ having a thienyl moiety $\left(\mathrm{IC}_{50} 36 \mu \mathrm{g} / \mathrm{mL}\right), \mathrm{BP}_{2}$ and $\mathrm{BP}_{6}$ having fluorophenyl and dichlorophenyl moieties respectively $\left(\mathrm{IC}_{50} 42 \mu \mathrm{g} / \mathrm{mL}\right), \mathrm{BP}_{1}$ having a methylphenyl moiety $\left(\mathrm{IC}_{50} 55 \mu \mathrm{g} / \mathrm{mL}\right)$ and $\mathrm{BP}_{14}$ having a bromofuran moiety ( $\mathrm{IC}_{50} 56 \mu \mathrm{g} / \mathrm{mL}$ ). The other compounds also showed activity but at a higher $\mathrm{IC}_{50}$ values.
Among the compounds tested for cytotoxicity on MCF-7 cell lines, the compound $\mathrm{BP}_{14}$ showed maximum activity ( $\left.\mathrm{IC}_{50} 27 \mu \mathrm{g} / \mathrm{mL}\right)$. This was followed by compounds, $\mathrm{BP}_{20}\left(\mathrm{IC}_{50} 28 \mu \mathrm{g} / \mathrm{mL}\right)$, $\mathrm{BP}_{5}\left(\mathrm{IC}_{50} 42 \mu \mathrm{g} / \mathrm{mL}\right)$ and $\mathrm{BP}_{2}\left(\mathrm{IC}_{50} 48 \mu \mathrm{g} / \mathrm{mL}\right)$. All the other compounds showed cytotoxicity at higher values.

Among the compounds tested for cytotoxicity on DU-145 cell lines, the compounds, $\mathrm{BP}_{14}$ and $\mathrm{BP}_{20}$ showed maximum activity ( $\mathrm{IC}_{50} 16 \mu \mathrm{g} / \mathrm{mL}$ ). This was followed by compounds, $\mathrm{BP}_{5}\left(\mathrm{IC}_{50} 33 \mu \mathrm{g} / \mathrm{mL}\right.$ ), $\mathrm{BP}_{11}$ having a 3-nitro-4-methylphenyl moiety $\left(\mathrm{IC}_{50}\right.$ $46 \mu \mathrm{g} / \mathrm{mL}), \mathrm{BP}_{1}\left(\mathrm{IC}_{50} 52 \mu \mathrm{g} / \mathrm{mL}\right)$ and $\mathrm{BP}_{6}\left(\mathrm{IC}_{50} 56\right.$ $\mu \mathrm{g} / \mathrm{mL})$. 
It was also observed that among all the compounds tested on these three cell lines, most of the compounds showed maximum activity on prostate cancer cell lines (DU-145).

ACKNOWLEDGMENTS: One of the authors (Venkata rao vutla) is thankful to the ACTREC Research center Mumbai for providing cytotoxic evaluation studies and to the Principal, Andhra University College of Pharmaceutical Sciences, Visakhapatnam for providing required help in carrying out the pharmacological studies

\section{REFERENCES:}

1. Anshu, D., Ruby, S., Dharmendra, S., Ashok, L., Asha, S. Phosphorus, Sulfur, Silicon Relat. Elem., 185; 2472:2010.

2. Ghotekar, D.S., Joshi, R.S., Mandhane, P.G., Bhagat, S.S., Gill, C.H. Indian J. Chem., Sect. B, 49B; 1267:2010.

3. Pant, S., Sharma, P., Pant, U.C. Phosphorus, Sulfur, Silicon Relat. Elem., 183; 2974:2008.

4. Desai, K.G., Desai, K.R. Indian J. Chem., Sect. B, 46B; 1179:2007.

5. Garg, N., Chandra, T., Archana; Jain, A.B., Kumar,A. Eur. J. Med. Chem., 45;1529:2010.

6. Sarro, G.D., Chimirri, A., Sarro, A.D., Gitto, R., Grasso, S., Zappala, M. Eur. J. Med. Chem., 30; 925:1995.

7. Saini, R.K., Joshi,Y.C., Joshi, P. Phosphorus, Sulfur, Silicon Relat. Elem., 183; 2181:2008.

8. Grandolini, G., Perioli, L., Ambrogi, V. Eur. J. Med. Chem., 34; 701:1999.

9. Yamada, S., Mori, Y., Morimatsu, K., Ishizu, Y., Ozaki, Y., Yoshioka, R., Nakatani, T., Seko, H. J. Org. Chem., 61; 8586:1996.
10. Maayan, S., Ohad, N. and Soliman, K., Bioorg. Med. Chem., 13; 433:2005.

11. Nowakowska, Eur. J. Med. Chem., 42; 125:2007.

12. Go, M.L., Wu, X. and Liu, X.L., Current Medicinal Chemistry, 12; 483:2005.

13. Mark, C. and Nagarathnam, D., J. Nat. Prod., 54; 1656:1991.

14. Wilson, C. W., J.Asian chem. Soc., 61; 2303:1938.

15. Claisen, L. and Claparede, A., Ber., 14;2463:1881.

16. Saravanamurugan, S., Palanichamy, M. and Banumathi, A., Catalysis Comm., 6; 399:2005.

17. Anjaneyulu, A.S.R., Sudha Rani, G., Mallavadhani, U.V. and Murthy, Y.L.N., Ind. J. Het. Chem., 4; 9; 1994.

18. Bala Krishna, K. and Ganesha Rani., Ind. J. Chem., 42B; 2556:2003.

19. Deshpande, A.M., Narshinha, P.A., Arvind, A.N. and Joseph, E., Bioorg. Med. Chem., 199: 7, 1237.

20. Kurokawa, J., Adachi-Akahane, S., Nagao, T. Eur. J. Pharmacol., 325; 229:1997.

21. Urbanski, M.J., Chen, R.H., Demarest, K.T., Gunnet, J., Look, R., Ericson, E., Murray, W.V., Rybczynski, P.J., Zhang, X. Bioorg. Med. Chem. Lett., 2003: 13; 403.

22. Di Santo, R., Costi, R. Farmaco, 60; 385:2005.

23. Kumar, A., Ahmad, I., Sudershan Rao, M. J Sulfur Chem., 30; 570:2009.

24. Hekmatshoar, R., Sadjadi, S., Shiri, S., Heravi, M.M., Beheshtiha,Y.S. Synth. Commun., 39;2549:2009.

25. Pan, X.-Q., Zou, J.-P., Huang, Z.-H., Zhang,W. Tetrahedron Lett., 49; 5302:2008.

26. Sharma, G., Kumar, R., Chakraborti, A.K. Tetrahedron Lett., 49; 4272:2008.

27. Sharma, G., Kumar, R., Chakraborti, A.K. Tetrahedron Lett., 49; 4269:2008.

28. Khatik, G.L., Kumar, R., Chakraborti, A.K. Synthesis, 4; 541:2007.

\section{How to cite this article:}

Vutla VR, Yejella RP and Nadendla R: Synthesis of novel 1, 5-dihydrobenzothiazepine derivatives by conventional and microwave irradiation methods and their pharmacological activities. Int J Pharm Sci Res 2014; 5(2): 453-62.doi: 10.13040/IJPSR. 0975-8232.5(2).453-62

All @ 2013 are reserved by International Journal of Pharmaceutical Sciences and Research. This Journal licensed under a Creative Commons Attribution-NonCommercial-ShareAlike 3.0 Unported License.

This article can be downloaded to ANDROID OS based mobile. Scan QR Code using Code/Bar Scanner from your mobile. (Scanners are available on Google Playstore) 